IZA DP No. 4408

Noncompliance and the Effects of the Minimum Wage on Hours and Welfare in Competitive Labor Markets

Leif Danziger

September 2009 


\title{
Noncompliance and the Effects of the Minimum Wage on Hours and Welfare in Competitive Labor Markets
}

\author{
Leif Danziger \\ Ben-Gurion University \\ and IZA
}

\section{Discussion Paper No. 4408 \\ September 2009}

\author{
IZA \\ P.O. Box 7240 \\ 53072 Bonn \\ Germany \\ Phone: +49-228-3894-0 \\ Fax: +49-228-3894-180 \\ E-mail: iza@iza.org
}

\begin{abstract}
Any opinions expressed here are those of the author(s) and not those of IZA. Research published in this series may include views on policy, but the institute itself takes no institutional policy positions.

The Institute for the Study of Labor (IZA) in Bonn is a local and virtual international research center and a place of communication between science, politics and business. IZA is an independent nonprofit organization supported by Deutsche Post Foundation. The center is associated with the University of Bonn and offers a stimulating research environment through its international network, workshops and conferences, data service, project support, research visits and doctoral program. IZA engages in (i) original and internationally competitive research in all fields of labor economics, (ii) development of policy concepts, and (iii) dissemination of research results and concepts to the interested public.
\end{abstract}

IZA Discussion Papers often represent preliminary work and are circulated to encourage discussion. Citation of such a paper should account for its provisional character. A revised version may be available directly from the author. 
IZA Discussion Paper No. 4408

September 2009

\section{ABSTRACT \\ Noncompliance and the Effects of the Minimum Wage on Hours and Welfare in Competitive Labor Markets}

This paper shows that increases in the minimum wage rate can have ambiguous effects on the working hours and welfare of employed workers in competitive labor markets. The reason is that employers may not comply with the minimum wage legislation and instead pay a lower subminimum wage rate. If workers are risk neutral, we prove that working hours and welfare are invariant to the minimum wage rate. If workers are risk averse and imprudent (which is the empirically likely case), then working hours decrease with the minimum wage rate, while their welfare may increase.

JEL Classification: J38

Keywords: noncompliance, minimum wage, working hours, welfare, competitive labor markets

Corresponding author:

Leif Danziger

Department of Economics

Ben-Gurion University

Beerh-Sheva 84105

Israel

E-mail: danziger@bgu.ac.il 


\section{Introduction}

The minimum wage rate is one of the cornerstones of protective labor legislation. Its purpose is to reduce income inequality by redistributing incomes toward the working poor, even if this is achieved at the cost of efficiency. However, the traditional view among economists is that the labor market for low-wage workers is reasonably competitive so that increases in the minimum wage rate have adverse consequences for some low-wage workers since employers' demand for labor falls. Ironically, then, the minimum wage legislation may end up harming many of those for whom it was intended to benefit.

There is persuasive empirical evidence that increases in the minimum wage rate reduce the number of employed workers in typical low-wage labor markets. For example, Neumark and Wascher (1992), Deere et al. (1995), and Burkhauser (2000) find a negative relation between the minimum wage rate and the number of employed workers in low-pay jobs. ${ }^{1}$ At the same time, there is conflicting empirical evidence about the effect of the minimum wage rate on working hours for the workers that remain employed. Thus, Neumark et al. (2004) find that working hours decrease with the minimum wage rate, while Zavodny (2000) finds that working hours increase with the minimum wage rate. Note, however, that the studies concerned with the number of employed workers have almost exclusively focused on teenagers, most of whom are only temporarily holding low-paying jobs. On the other hand, working-hour studies are, by their very nature, mostly concerned with adult breadwinners who are permanently attached to low-wage labor markets and whose well-being is likely to be greatly affected by changes in working hours. Thus, the policy objective of reducing income inequality is, arguably, more closely related to improving the earning prospects of low-pay adult workers whose income is the primary source of support for themselves and their dependents, rather than to reducing the job losses of teenagers who are often destined to be employed in high-paying jobs in the future. This paper therefore examines how the minimum wage rate affects the competitively determined working hours and welfare of the

\footnotetext{
${ }^{1}$ However, Card and Krueger (1995) conclude that minimum wage increases may have either negligible or positive effects on employment, which they account for by suggesting that market imperfections may make employers behave monopsonistically. See Neumark and Wascher (2007) for a comprehensive survey of the recent empirical literature for the U.S. and many other countries.
} 
mainly adult workers who are permanently employed in low-wage labor markets, and, for simplicity, ignores changes in the number of employed workers.

The model in this paper explicitly incorporates that firms may not comply with the minimum-wage legislation, which gives rise to a competitively determined endogenous subminimum wage rate that depends on the minimum wage rate. ${ }^{2}$ This is important, because there is ample evidence that noncompliance with the minimum-wage legislation is rampant. Thus, Ashenfelter and Smith (1979) estimate from the 1975 Current Population Survey that the overall compliance rate is only $60 \%$, and for males aged 17-19 a mere 35\%. More recently, Weil (2005) used the year-2000 Department of Labor survey of the apparel industry in the Los Angeles area to show that only $46 \%$ of the employers comply with the statutory minimum wage rate and that $27 \%$ of the workers are paid less than the minimum wage rate. Finally, Cortes (2005), based on the 1997 and 1998 Current Population Survey, estimates that the compliance rate is only $28 \%$ for native males and $20 \%$ for immigrant males.

The reason for the low rate of compliance with the minimum-wage legislation seems to be that enforcement is generally quite lax. First, the probability that a noncomplying firm will be caught is small. In fact, the annual likelihood that a firm will even be inspected by the Wage and Hour Division of the Department of Labor is less than 10\% (Weil, 2005). Second, the penalty for a noncomplying firm that is caught is minimal. Indeed, it typically consists of no more than having to pay workers back wages equalling the difference between the minimum wage rate and the subminimum wage rate already paid, and no government fine is imposed (Ashenfelter and Smith, 1979). Even if the firm is subject to additional penalties, it can still expect to gain from noncompliance as long as the expected wage rate

\footnotetext{
${ }^{2}$ Previous theoretical models of noncompliance in Ashenfelter and Smith (1979), Grenier (1982), Chang and Ehrlich (1985), and Yaniv (2001) take the subminimum wage rate as exogenous and ignore that workers may adjust their labor supply in response to the uncertainty arising from not knowing whether a noncomplying firm will be caught. Yaniv (2004) allows for an endogenous subminimum wage rate in a model with risk-neutral workers, and asserts (without proof) that noncompliance has an ambiguous effect on employment and makes workers worse off. However, these conclusions are incorrect as will be shown below. Basu et al. (2009) analyze a model in which both the subminimum wage rate and the enforcement intensity are endogenous. Danziger (2009) shows that if the subminimum wage rate is endogenous and the working hours are fixed, then the minimum wage rate turns small firms into endogenous monopsonists. See Card and Krueger (1995), Strobl and Walsh (2003), and Gindling and Terrell (2009) for empirical evidence about the relationship between the minimum and subminimum wage rates.
} 
(defined as the subminimum wage rate plus the probability that the firm is caught times the penalties the firm is then obliged to pay) is less than the minimum wage rate. Accordingly, the minimum-wage legislation has a built-in incentive for noncompliance. By paying only the illegal subminimum wage rate, a firm takes a calculated gamble with a positive expected payoff. $^{3}$

The paper provides a comprehensive analysis of the equilibrium effects of the minimum wage rate on working hours and welfare in an otherwise competitive labor market. The endogeneity of the subminimum wage rate plays a crucial role in the analysis. If workers are risk neutral, an increase in the minimum wage rate causes the subminimum wage rate to decrease to the extent needed to leave the expected wage rate unaffected. The working hours in the competitive equilibrium are, therefore, unchanged, and the introduction of a minimum wage rate and increases in its size have no welfare effects. In the empirically more relevant case that workers are income risk averse, the effects of the minimum wage rate depend on the workers' relative prudence. In particular, if workers are imprudent (as appears likely), an increase in the minimum wage rate reduces the subminimum wage rate by less than required to keep the expected wage rate unchanged. The higher expected wage rate means that the increase in the minimum wage rate reduces working hours, may increase the workers' welfare, and reduces expected profits. On the other hand, if workers are prudent (which appears unlikely), an increase in the minimum wage rate reduces the subminimum wage rate so much that the expected wage rate decreases. This leads to increased working hours, a reduction in workers' welfare, and increased profits. ${ }^{4}$

\footnotetext{
3 Workers who are underpaid only rarely complain to the Wage and Hour Division of the Department of Labor, presumably out of fear that they will be marked as trouble makers and that the employer will retaliate by dismissing the complainants. Note that the employer cannot be sued for back wages unless the workers are willing to testify in open court, and that many of the underpaid workers are illegal immigrants.

${ }^{4}$ In contrast, if the subminimum wage rate were fixed exogenously, the qualitative results would be the same as with full compliance with the minimum wage rate: An increase in the minimum wage rate would always increase in the expected wage, and hence always decrease working hours which must be rationed. The effect on workers' welfare would depend on their risk preferences, while profits would always decrease.
} 


\section{The Model}

Consider a labor market with a unit continuum of homogeneous workers and a unit continuum of homogeneous employers. A worker's utility is given by $u(y)-v(h), u^{\prime}(y)>0$ and $v^{\prime}(h)>0$, where $y$ denotes the worker's income from work and $h$ denotes the time spent working. For a given wage rate $w>0$, a worker's labor income is $y=w h$, and the corresponding utility is $u(w h)-v(h)$. A worker chooses how much to work in order to maximize his utility. This implies that a worker's labor supply is a function $h(w)$ of the wage rate, and, assuming an internal solution, is determined by $w u^{\prime}(y)-v^{\prime}(h)=0$. It is also assumed that $u^{\prime}(y)+y u^{\prime \prime}(y)>0$, so that the labor supply increases with the wage rate. ${ }^{5}$ A positive effect of a minimum wage rate on working hours cannot then be attributed to the labor supply being a backward-bending function of the wage rate.

Each employer's production is given by $f(\ell), f^{\prime}>0$ and $f^{\prime \prime}<0$, where $\ell$ denotes labor input. Normalizing the price of output to one, an employer's profit is $f(\ell)-w \ell$. An employer chooses the labor input in order to maximize profit. The demand for labor can therefore be written as a function $\ell(w)$ of the wage rate, and, assuming an internal solution, is determined by $f^{\prime}(\ell)-w=0$. Since $f^{\prime \prime}<0$, the demand for labor decreases with the wage rate.

The labor market is competitive, and the equilibrium wage rate with no minimum-wage legislation is denoted by $w_{c}$. Since the measures of workers and employers are equal, $w_{c}$ is obtained by solving $h\left(w_{c}\right)=\ell\left(w_{c}\right)$.

Suppose that a minimum-wage legislation is enacted with a statutory minimum wage rate $m$ that exceeds $w_{c}$. However, employers may choose to violate the law by paying only the lower subminimum wage rate $w_{1}$. This subminimum wage rate equalizes supply and demand for labor in the competitive labor market that internalizes that noncomplying employers will

${ }^{5}$ Differentiating $w u^{\prime}(y)-v^{\prime}(h)=0$ with respect to $w$ yields

$$
\begin{aligned}
\frac{d h(w)}{d w} & =-\frac{d\left[w u^{\prime}(y)-v^{\prime}(h)\right] / d w}{d\left[w u^{\prime}(y)-v^{\prime}(h)\right] / d h} \\
& =-\frac{u^{\prime}(y)+y u^{\prime \prime}(y)}{w^{2} u^{\prime \prime}(y)-v^{\prime \prime}(h)}
\end{aligned}
$$

which is positive since $w^{2} u^{\prime \prime}(y)-v^{\prime \prime}(h)<0$ from the second-order condition for a maximum. The assumption implies that a worker's relative risk aversion is less than 1 . 
sometimes be detected and penalized.

The probability that a noncomplying employer will be detected is $\phi \in(0,1)$. If detected, the employer must retroactively compensate workers with a backpay which, including awards, is proportional to the gap between the minimum wage rate and the subminimum wage rate that was actually paid. Stated formally, the backpay is $\beta\left(m-w_{1}\right)$, where $\beta \geq 1$ is the constant penalty rate. Thus, the subminimum wage rate augmented by the backpay is $w_{2} \equiv w_{1}+\beta\left(m-w_{1}\right)$. Taking this into account, the expected wage rate is $w^{*} \equiv(1-$ $\phi) w_{1}+\phi w_{2}=w_{1}+\phi \beta\left(m-w_{1}\right)$. It is assumed that the expected backpay is less than the underpayment, $\phi \beta<1$, which is what provides employers with the incentive to violate the minimum-wage legislation. It is also assumed that $w^{*}>\phi \beta m$, so that $w_{1}>0$.

Employers are risk neutral and choose to pay less than the mandated minimum wage rate in order to maximize their expected profit $f(\ell)-w^{*} \ell$. Hence, the labor demand is determined solely by the expected wage rate and therefore depends on the minimum wage rate only to the extent that the latter affects the expected wage rate. Similarly, the labor demand does not directly depend on the subminimum wage rate, the penalty rate, or the probability of detection. In other words, the employers' demand for labor is the same as if $w^{*}$ were a certain wage rate. The demand is therefore given by $\ell\left(w^{*}\right)$.

\section{Risk-Neutral Workers}

In this section we assume that workers are income risk neutral, i.e., $u^{\prime \prime}(y)=0$. A worker is then only concerned with the expected wage rate and not with the extent to which it is uncertain. His utility can be taken to be $w h-v(h)$, and he chooses how much to work in order to maximize his expected utility $w^{*} h-v(h)$. For a given $w^{*}$, the expected utility is independent of $m$, and the supply of labor is therefore also independent of $m$. Accordingly, the supply of labor is the same as if $w^{*}$ were a certain wage rate and is given by $h\left(w^{*}\right)$.

In equilibrium, the expected wage rate satisfies $h\left(w^{*}\right)=\ell\left(w^{*}\right)$ and is identical to the equilibrium wage rate in the absence of a minimum wage rate, i.e., $w^{*}=w_{c}$. The explanation is that the competitively determined subminimum wage adjusts to $w_{1}=\left(w_{c}-\phi \beta m\right) /(1-\phi \beta)$, which is sufficiently below $w_{c}$ so that the expected wage rate is reduced to $w_{c}$. 
Because the subminimum wage rate is endogenous in the competitive equilibrium, neither the minimum wage rate itself, nor the penalty rate, nor the probability that noncompliance will be detected have any effect on the expected wage rate. It follows then that the equilibrium working hours with a statutory minimum wage rate are identical to the equilibrium working hours in the absence of a statutory minimum wage rate. Thus, in the case of riskneutral workers, the expected wage rate and the equilibrium working hours are invariant to the introduction of a minimum wage rate and to changes in its level. Furthermore, since both the workers' expected utility and the employers' expected profit are also invariant, the minimum wage rate has no welfare effects.

\section{Risk-Averse Workers}

For the remainder of the paper we assume that workers are income risk averse, i.e., $u^{\prime \prime}(y)<$ 0 . A worker is then adversely affected by the income risk stemming from the uncertainty about whether the subminimum market wage rate will be augmented by a backpay. The subminimum wage rate can be written as $w_{1}=\left(w^{*}-\phi \beta m\right) /(1-\phi \beta)$ and the augmented subminimum wage rate as $w_{2}=\left[(1-\beta) w^{*}+(1-\phi) \beta m\right] /(1-\phi \beta)$. The workers' corresponding incomes are $y_{1} \equiv w_{1} h$ and $y_{2} \equiv w_{2} h$. Thus, holding the expected wage rate constant, for a given labor supply a higher minimum wage rate is associated with a lower $y_{1}$ and a higher $y_{2}$, and hence with a riskier income.

The income uncertainty might influence the labor supply which is found by maximizing a worker's expected utility

$$
E u(y)-v(h)=(1-\phi) u\left(y_{1}\right)+\phi u\left(y_{2}\right)-v(h)
$$

For a given $\beta$ and $\phi$, the labor supply is now a function $h\left(w^{*}, m\right)$ of $w^{*}$ and $m$, and assuming an internal solution, satisfies $E\left[w u^{\prime}(y)\right]-v^{\prime}(h)=0$.

\subsection{Equilibrium Working Hours and Expected Wage Rate}

In order to clear the labor market, the expected wage rate has to satisfy the equilibrium condition $h\left(w^{*}, m\right)=\ell\left(w^{*}\right)$. To determine the effect of the minimum wage rate on the 
expected wage rate, we differentiate the equilibrium condition with respect to $m$, yielding

$$
\frac{d w^{*}}{d m}=\frac{\partial h / \partial m}{\partial \ell / \partial w^{*}-\partial h / \partial w^{*}}
$$

The equilibrium working hours are denoted by $H$. Since $d H / d m=\left(\partial \ell / \partial w^{*}\right)\left(d w^{*} / d m\right)$, the effect of the minimum wage rate on the equilibrium working hours is in the opposite direction of its effect on the expected wage rate, and given by

$$
\frac{d H}{d m}=\frac{\partial h / \partial m}{1-\left(\partial h / \partial w^{*}\right) /\left(\partial \ell / \partial w^{*}\right)},
$$

The denominator of $d H / d m$ is positive (since $\partial \ell / \partial w^{*}<0$ and $u^{\prime}(y)+y u^{\prime \prime}(y)>0 \Rightarrow$ $\partial h / \partial w^{*}>0$ ). The numerator is the effect of an increase in the minimum wage rate (for a given $\left.w^{*}\right)$ on labor supply, and it is obtained by differentiating $E\left[w u^{\prime}(y)\right]-v^{\prime}(h)=0$ with respect to $m$, which yields

$$
\frac{\partial h}{\partial m}=-\frac{\partial E\left[w u^{\prime}(y)\right] / \partial m}{E\left[w^{2} u^{\prime \prime}(y)\right]-v^{\prime \prime}(h)} .
$$

Since $E\left[w^{2} u^{\prime \prime}(y)\right]-v^{\prime \prime}(h)<0$ from the second-order condition for a maximum, $\partial h / \partial m$ and hence $d H / d m$ has the same sign as $\partial E\left[w u^{\prime}(y)\right] / \partial m$, or equivalently, as $\partial E\left[y u^{\prime}(y)\right] / \partial m$, which is the effect of an increase in the minimum wage rate on the expected value of the incomeweighted marginal utility of income, $E\left[y u^{\prime}(y)\right]$. Thus, due to the income uncertainty created by the imperfectly enforced minimum wage rate, the impact on the equilibrium working hours of an increase in the minimum wage rate depends on the curvature of $y u^{\prime}(y)$ : there is no effect if $y u^{\prime}(y)$ is linear, a negative effect if $y u^{\prime}(y)$ is concave, and a positive effect if $y u^{\prime}(y)$ is convex.

The change in the labor supply constitutes the optimal compromise between two opposing forces: on the one hand, the increased riskiness of the wage rate makes it less attractive to work, which tends to reduce the labor supply; on the other hand, the increased riskiness of the wage rate also makes it more essential to hedge against the income risk by making a precautionary increase in the labor supply. The overall effect of an increase in the minimum wage rate on the labor supply can be precisely described in terms of the workers' relative prudence, which is defined as $P(y) \equiv-y u^{\prime \prime \prime}(y) / u^{\prime \prime}(y)$ (Kimball, 1990). Since $\partial^{2}\left[y u^{\prime}(y)\right] / \partial y^{2}=-u^{\prime \prime}(y)[P(y)-2]$, it follows that $y u^{\prime}(y)$ is linear in $y$ if $P(y)=2$, concave 
in $y$ if $P(y)<2$, and convex in $y$ if $P(y)>2$. An increase in the minimum wage rate and the consequent risk therefore has no effect on the equilibrium working hours if the relative prudence equals two, but reduces the equilibrium working hours if the relative prudence is less than two, i.e., if the workers are "imprudent", and increases the equilibrium working hours if the relative prudence exceeds two, i.e., if the workers are "prudent". Consequently, in the case of risk-averse workers, the legislation of a minimum wage rate or an increase in an existing minimum wage rate has a theoretically ambiguous effect on working hours. However, since empirical estimates of relative prudence are very low, ${ }^{6}$ it follows that in practice, an increase in the minimum wage rate is likely to be associated with a decrease in working hours.

The change in labor supply, which gives rise to a proportional change in the expected income, can be understood as the workers' optimal precautionary reaction to increased income risk at a given expected wage rate. Thus, the change in labor supply is analogous to the response of precautionary savings in the face of increased risk of the return on savings at a given expected interest rate. In both cases, the question is how much of a certain utility to sacrifice (in the minimum-wage case by working more and in the precautionarysavings case by reducing current consumption) in exchange for a higher expected value of an uncertain income. Thus, just as the optimal savings is the same at all levels of risk if the relative prudence equals two, the optimal labor supply is also invariant to risk if the relative prudence equals two. Further, since the precautionary motive causes risk to have a negative or positive effect on savings depending on whether savers are imprudent or prudent, it similarly causes risk to have a negative or positive effect on labor supply depending on whether workers are imprudent or prudent. ${ }^{7}$

While the signs of $d H / d m$ and $d w^{*} / d m$ are not affected by how the labor supply and demand change with the minimum wage rate, their magnitudes are. Thus, it is clear from (1) and (2) that the more labor supply increases with $w^{*}$ (i.e., the larger is $d h / d w^{*}$ ), the less

\footnotetext{
${ }^{6}$ The findings in Dynan (1993), Guiso et al. (1992), and Parker (1999) indicate that the relative prudence is close to zero.

${ }^{7}$ See Parker et al. (2005) and Flodén et al. (2006) for studies of the impact of wage uncertainty on labor supply.
} 
responsive are the equilibrium working hours and the expected wage rate to an increase in $m$ (i.e., the smaller are the absolute values of $d H / d m$ and $d w^{*} / d m$ ). On the other hand, the more the demand decreases with $w^{*}$ (i.e., the smaller is $\left.\partial \ell / \partial w^{*}\right)$, the more the equilibrium working hours and the less the expected wage rate respond to an increase in $m$ (i.e., the larger is the absolute value of $d H / d m$ and the smaller is the absolute value of $\left.d w^{*} / d m\right){ }^{8}$

\subsection{Welfare}

We now turn to the welfare effects of a minimum wage rate. Since a competitive equilibrium without a minimum wage rate is Pareto optimal, it is impossible that both workers and employers gain from a minimum wage rate. In other words, if one group gains, it must be at the expense of the other, and both groups may lose.

First, we examine the effect of an increase in the minimum wage rate on the workers' expected utility. For a given expected wage rate, the expected utility is exposed to an uncertainty effect that stems from the increase in income uncertainty caused by an increase in the minimum wage rate. The uncertainty effect is always negative. Additionally, unless the workers' relative prudence equals two, an increase in the minimum wage rate changes the equilibrium expected wage rate, and this change has an expected-wage effect on the workers' expected utility. If the workers are imprudent and the expected wage rate therefore increases, the expected-wage effect is positive. The gain from the higher expected wage rate may then outweigh the loss from the increased uncertainty. On the other hand, if the workers are prudent and the expected wage rate therefore decreases, the expected-wage effect is negative. The uncertainty and expected-wage effects of an increase in the minimum wage rate then both reduce the workers' expected utility. This is true even though working hours increase, since such an increase is generated by an increase in the workers' labor supply which only serves to ameliorate the negative impact of the increased uncertainty.

To obtain a precise assessment of how the minimum wage rate affects the workers' ex-

\footnotetext{
8 The model assumes that the output price is fixed. However, a higher $w^{*}$ increases production costs and possibly also the demand for the firms' product (if the elasticity of the labor demand with respect to $w^{*}$ exceeds -1 and the product is normal (see Kennan, 1995)), both of which could lead to a higher price. Such a price increase would be equivalent to having a larger value of $\partial \ell / \partial w^{*}$ and would therefore not affect the signs of $d H / d m$ and $d w^{*} / d m$.
} 
pected utility, we differentiate $E u(y)-v(h)$ with respect to $m$. If $S(y) \equiv-y u^{\prime \prime}(y) / u^{\prime}(y)$ denotes the relative risk aversion at income $y$, and

$$
\begin{aligned}
A & \equiv \frac{(1-\phi) \phi \beta h\left[u^{\prime}\left(y_{1}\right)-u^{\prime}\left(y_{2}\right)\right]}{(1-\phi \beta)\left(\partial h / \partial w^{*}-\partial \ell / \partial w^{*}\right)} \\
B & \equiv \frac{1}{\left[1 / u^{\prime}\left(y_{1}\right)-1 / u^{\prime}\left(y_{2}\right)\right]\left\{E\left[w^{2} u^{\prime \prime}(y)\right]-v^{\prime \prime}(h)\right\}}
\end{aligned}
$$

(both $A$ and $B$ are positive), then Appendix A shows that

$$
\frac{d[E u(y)-v(h)]}{d m}=A\left\{B\left[S\left(y_{2}\right)-S\left(y_{1}\right)\right]+\frac{1}{f^{\prime \prime}(\ell)}\right\} .
$$

To understand this expression, consider a hypothetical case where the demand for labor is completely inelastic, i.e., $\partial \ell / \partial w^{*}=1 / f^{\prime \prime}(\ell)=0$. An increase in the minimum wage rate would then not change the equilibrium working hours, so that, according to eq. (3), the effect on workers' expected utility would have the same sign as $S\left(y_{2}\right)-S\left(y_{1}\right)$. Hence, if the relative risk aversion is constant, the positive expected-wage effect of an increase in the minimum wage rate exactly offsets the negative uncertainty effect, leaving the workers' expected utility unchanged. If the relative risk aversion is increasing, then the expected-wage effect is positive and so large that it dominates the negative uncertainty effect, causing the workers' expected utility to increase. If the relative risk aversion is decreasing, then even a positive expected-wage effect cannot offset the negative uncertainty effect and the workers' expected utility decreases.

The explanation for the above relationship between the workers' relative risk aversion and their expected utility is that, on the assumption that the demand for labor is completely inelastic, an increase in the minimum wage rate would cause the expected wage rate to adjust sufficiently such that the income-weighted marginal utility of income, $E\left[y u^{\prime}(y)\right]$, and hence the workers' labor supply, would be unchanged. The combined uncertainty and expectedwage effects on the workers' expected utility, $E u(y)-v(h)$, would then depend solely on how $u(y)$ changes with $y u^{\prime}(y)$. Observe that an increase in the minimum wage rate reduces $y_{1}$ and hence $y_{1} u^{\prime}\left(y_{1}\right)$, and increases $y_{2}$ and hence $y_{2} u^{\prime}\left(y_{2}\right)$. Also, observe that $u(y)$ is a linear, convex, or concave function of $y u^{\prime}(y)$ depending on whether the relative risk aversion 
is constant, increasing, or decreasing. ${ }^{9}$ Accordingly, the workers' expected utility would be unchanged if their relative risk aversion is constant, would increase if their relative risk aversion increases, and would decrease if their relative risk aversion decreases. ${ }^{10}$

In contrast to this hypothetical case, in reality the demand for labor is not completely inelastic. Accordingly, except if the relative prudence equals two and uncertainty does not affect the labor supply, the sensitivity of the demand for labor to $w^{*}$ influences the expectedwage effect of an increase in the minimum wage rate. For all other values of the relative prudence, the more the demand for labor decreases with $w^{*}$ (i.e., the smaller is $\partial \ell / \partial w^{*}$ ), the smaller is the absolute change in $w^{*}$ (see eq. (1)) and hence in the expected-wage effect. Consequently, eq. (3) shows that an increase in the minimum wage rate will increase the workers' expected utility if their relative risk aversion is sufficiently increasing, but will otherwise decrease the workers' expected utility.

Next, we examine the effect of a minimum wage rate on the employers' expected profit. For a given expected wage rate, the expected profit is unaffected by uncertainty. The effect of an increase in the minimum wage rate on the expected profit is therefore fully determined by its effect on the equilibrium expected wage rate. Thus, if the workers' relative prudence equals two and the expected wage rate is unchanged, then the expected profit is also unchanged. On the other hand, if the workers are imprudent and the expected wage rate increases, then the expected profit decreases, while if the workers are prudent and the expected wage rate decreases, the expected profit increases.

${ }^{9}$ Differentiating $u(y)$ twice with respect to $y u^{\prime}(y)$ yields

$$
\frac{d^{2} u(y)}{d\left[y u^{\prime}(y)\right]^{2}}=\frac{S^{\prime}(y)}{u^{\prime}(y)[1-S(y)]^{3}},
$$

which has the same sign as $S^{\prime}(y)$.

${ }^{10}$ Barsky et al. (1997) and Guiso and Paiella (2008) provide empirical evidence of increasing relative risk aversion. 


\section{The Penalty Rate and The Probability of Detection}

To determine the effect of an increase in the penalty rate on the expected wage rate, we differentiate $h\left(w^{*}, m\right)=\ell\left(w^{*}\right)$ with respect to $\phi$. This yields

$$
\frac{d w^{*}}{d \beta}=\frac{\partial h / \partial \beta}{\partial \ell / \partial w^{*}-\partial h / \partial w^{*}} .
$$

The corresponding effect on the working hours is given by

$$
\frac{d H}{d \beta}=\frac{\partial h / \partial \beta}{1-\left(\partial h / \partial w^{*}\right) /\left(\partial \ell / \partial w^{*}\right)} .
$$

Accordingly, $d H / d \beta$ has the same sign as the effect of an increase in the penalty rate (for a given $w^{*}$ ) on the labor supply, which in turn has the same sign as the effect of an increase in the penalty rate on the expected value of the income-weighted marginal utility of income, $E\left[y u^{\prime}(y)\right]$. The sign of $d w^{*} / d \beta$ is the opposite of that of $d H / d \beta$.

For a given expected wage rate, an increase in the penalty rate leads to an increase in the backpay workers receive if a noncomplying employer is detected. Hence, the augmented subminimum wage rate increases, and therefore the subminimum wage rate itself must decrease. Accordingly, the workers' income uncertainty increases. It follows that the qualitative results obtained for an increase in the minimum wage rate on working hours and welfare hold also for an increase in the penalty rate. An increase in penalty rate is, therefore, a substitute for an increase in the minimum wage rate.

To determine the effect of an increase in the probability that a noncomplying firm is detected on the expected wage rate, we differentiate $h\left(w^{*}, m\right)=\ell\left(w^{*}\right)$ with respect to $\phi$. This yields

$$
\frac{d w^{*}}{d \phi}=\frac{\partial h / \partial \phi}{\partial \ell / \partial w^{*}-\partial h / \partial w^{*}}
$$

The corresponding effect on the working hours is given by

$$
\frac{d H}{d \phi}=\frac{\partial h / \partial \phi}{1-\left(\partial h / \partial w^{*}\right) /\left(\partial \ell / \partial w^{*}\right)} .
$$

Accordingly, $d H / d \phi$ has the same sign as the effect of an increase in the probability of detection (for a given $w^{*}$ ) on the labor supply and hence on the expected value of the 
income-weighted marginal utility of income. The sign of $d w^{*} / d \phi$ is the opposite of that of $d H / d \phi$.

For a given expected wage rate, a higher probability of detection not only raises the likelihood that workers receive $w_{2}$ and lowers the likelihood that they receive only $w_{1}$, it also decreases $w_{1}$ and either leaves $w_{2}$ unchanged (if $\beta=1$ ) or increases $w_{2}$ (if $\beta>1$ ). Consequently, an increase in $\phi$ is associated with a riskier income for the workers, and the direction of the change in working hours depends on the workers' relative prudence in a similar way as for an increase in $m$.

Turning to the welfare effects of an increase in the probability of detection, Appendix B shows that the direction of the effect on the workers' expected utility depends on the workers' relative risk aversion in a similar way as for an increase in the minimum wage rate. ${ }^{11}$ Since the firms' expected profit varies inversely with the expected wage rate, it can be concluded that the qualitative implications of an increase in the probability of detection on working hours and welfare are similar to those obtained for an increase in the minimum wage rate. Accordingly, like an increase in the penalty rate, an increase in the probability of detection is a substitute for an increase in the minimum wage rate.

\section{Conclusion}

This paper has shown that increases in the minimum wage rate can have an ambiguous effect on the working hours of employed workers (as distinct from the number of employed workers) and on their welfare in competitive labor markets. The reason is that employers can choose not to comply with the minimum wage legislation and instead pay only the lower subminimum wage rate. Employers that are caught paying less than the mandated minimum wage rate must pay back wages and possibly other penalties. The labor demand of noncomplying employers therefore depends solely on the expected wage rate, which is less than the minimum wage rate. The uncertainty about whether a noncomplying employer will be caught and penalized may affect the workers' labor supply, which therefore will depend on

\footnotetext{
11 The determination of the welfare effects cannot rely on the proof for an increase in the minimum wage rate which assumes that the probabilities of receiving $w_{1}$ and $w_{2}$ are unchanged.
} 
both the expected wage rate and the minimum wage rate. In particular, in the empirically likely case that workers are imprudent, the additional uncertainty associated with an increase in the minimum wage rate will lead to a decrease in the labor supply and hence in working hours in the competitive equilibrium.

An interesting implication of the model in this paper is that increases in the penalty rate or in the probability of detection can be used as substitutes for increases in the minimum wage rate. This may be important in practice since increasing the penalty rate (e.g., by encouraging workers to sue for liquidated damages) or increasing the probability of detection (e.g., by inspecting more firms) can be done administratively and are therefore politically easier to implement than increasing the minimum wage rate which would require legislative action. 


\section{Appendix A}

\section{The Minimum Wage Rate and Workers' Expected Utility}

Differentiate the expected utility with respect to $m$. This yields

$$
\frac{d[E u(y)-v(h)]}{d m}=\frac{\partial E u(y)}{\partial m}+\frac{\partial E u(y)}{\partial w^{*}} \frac{d w^{*}}{d m},
$$

where the first term is the uncertainty effect of an increase in the minimum wage rate and the second term is the expected-wage effect of the increase. By the envelope theorem, a change in $h$ due to changes in $m$ and $w^{*}$ has no effect on the expected utility. Substituting $d w^{*} / d m$ from (1),

$$
\begin{gathered}
\frac{d[E u(y)-v(h)]}{d m}=\frac{\partial E u(y)}{\partial m}+\frac{\partial E u(y)}{\partial w^{*}} \frac{\partial h / \partial m}{\partial \ell / \partial w^{*}-\partial h / \partial w^{*}} \\
=\frac{1}{\partial h / \partial w^{*}-\partial \ell / \partial w^{*}}\left[\frac{\partial E u(y)}{\partial m}\left(\frac{\partial h}{\partial w^{*}}-\frac{\partial \ell}{\partial w^{*}}\right)-\frac{\partial E u(y)}{\partial w^{*}} \frac{\partial h}{\partial m}\right],
\end{gathered}
$$

which equals

$$
\begin{aligned}
& \frac{(1-\phi) \phi \beta h}{(1-\phi \beta)\left[\partial h / \partial w^{*}-\partial \ell / \partial w^{*}\right]} \\
& {\left[\left[-u^{\prime}\left(y_{1}\right)+u^{\prime}\left(y_{2}\right)\right]\left(\frac{(1-\phi)\left[u^{\prime}\left(y_{1}\right)+y_{1} u^{\prime \prime}\left(y_{1}\right)\right]+\phi(1-\beta)\left[u^{\prime}\left(y_{2}\right)+y_{2} u^{\prime \prime}\left(y_{2}\right)\right]}{-(1-\phi \beta)\left\{E\left[w^{2} u^{\prime \prime}(y)\right]-v^{\prime \prime}(h)\right\}}-\frac{1}{f^{\prime \prime}(\ell)}\right)\right.} \\
& \left.-\left[(1-\phi) u^{\prime}\left(y_{1}\right)+\phi(1-\beta) u^{\prime}\left(y_{2}\right)\right] \frac{\left[-u^{\prime}\left(y_{1}\right)-y_{1} u^{\prime \prime}\left(y_{1}\right)+u^{\prime}\left(y_{2}\right)+y_{2} u^{\prime \prime}\left(y_{2}\right)\right]}{-(1-\phi \beta)\left\{E\left[w^{2} u^{\prime \prime}(y)\right]-v^{\prime \prime}(h)\right\}}\right] \\
= & A\left\{B\left[S\left(y_{2}\right)-S\left(y_{1}\right)\right]+\frac{1}{f^{\prime \prime}(\ell)}\right\} .
\end{aligned}
$$

\section{Appendix B}

\section{The Probability of Detection and Workers' Expected Utility}

Differentiate the expected utility with respect to $\phi$. This yields

$$
\frac{d[E u(y)-v(h)]}{d \phi}=\frac{\partial E u(y)}{\partial \phi}+\frac{\partial E u(y)}{\partial w^{*}} \frac{d w^{*}}{d \phi},
$$

where the first term is the uncertainty effect of an increase in the probability of detection and the second term is the expected-wage effect of the increase. By the envelope theorem, 
a change in $h$ due to changes in $\phi$ and $w^{*}$ has no effect on the expected utility. Substituting for $d w^{*} / d \phi$,

$$
\begin{aligned}
\frac{d[E u(y)-v(h)]}{d \phi} & =\frac{\partial E u(y)}{\partial \phi}+\frac{\partial E u(y)}{\partial w^{*}} \frac{\partial h / \partial \phi}{\partial \ell / \partial w^{*}-\partial h / \partial w^{*}} \\
& =\frac{1}{\partial h / \partial w^{*}-\partial \ell / \partial w^{*}}\left[\frac{\partial E u(y)}{\partial \phi}\left(\frac{\partial h}{\partial w^{*}}-\frac{\partial \ell}{\partial w^{*}}\right)-\frac{\partial E u(y)}{\partial w^{*}} \frac{\partial h}{\partial \phi}\right],
\end{aligned}
$$

which equals

$$
\begin{aligned}
& \frac{1}{\partial h / \partial w^{*}-\partial \ell / \partial w^{*}}\left(-\frac{\left[u\left(y_{2}\right)-u\left(y_{1}\right)\right]\left\{(1-\phi)\left[u^{\prime}\left(y_{1}\right)+y_{1} u^{\prime \prime}\left(y_{1}\right)\right]+\phi(1-\beta)\left[u^{\prime}\left(y_{2}\right)+y_{2} u^{\prime \prime}\left(y_{2}\right)\right]\right\}}{(1-\phi \beta)\left\{E\left[w^{2} u^{\prime \prime}(y)\right]-v^{\prime \prime}(h)\right\}}\right. \\
& \left.-\frac{\partial E u(y)}{\partial \phi} \frac{1}{f^{\prime \prime}(\ell)}+\frac{\left[(1-\phi) u^{\prime}\left(y_{1}\right)+\phi(1-\beta) u^{\prime}\left(y_{2}\right)\right]\left[-y_{1} u^{\prime}\left(y_{1}\right)+y_{2} u^{\prime}\left(y_{2}\right)\right]}{(1-\phi \beta)\left\{E\left[w^{2} u^{\prime \prime}(y)\right]-v^{\prime \prime}(h)\right\}}\right) \\
= & \frac{\psi}{\partial h / \partial w^{*}-\partial \ell / \partial w^{*}}\left(\left[u\left(y_{2}\right)-u\left(y_{1}\right)\right]\left\{\left[u^{\prime}\left(y_{1}\right)+y_{1} u^{\prime \prime}\left(y_{1}\right)\right]-\gamma\left[u^{\prime}\left(y_{2}\right)+y_{2} u^{\prime \prime}\left(y_{2}\right)\right]\right\}\right. \\
& \left.-\frac{\partial E u(y)}{\partial \phi} \frac{1}{f^{\prime \prime}(\ell) \psi}-\left[u^{\prime}\left(y_{1}\right)-\gamma u^{\prime}\left(y_{2}\right)\right]\left[-y_{1} u^{\prime}\left(y_{1}\right)+y_{2} u^{\prime}\left(y_{2}\right)\right]\right),
\end{aligned}
$$

where

$$
\psi \equiv \frac{\phi-1}{(1-\phi \beta)\left\{E\left[w^{2} u^{\prime \prime}(y)\right]-v^{\prime \prime}(h)\right\}}
$$

is positive, and $\gamma \equiv \phi(\beta-1) /(1-\phi)$.

If the demand for labor is completely inelastic (i.e., $\left.1 / f^{\prime \prime}(\ell)=0\right)$, the sign of $d[E u(y)-$ $v(h)] / d \phi$ is identical to that of

$$
\begin{aligned}
& {\left[u\left(y_{2}\right)-u\left(y_{1}\right)\right]\left\{\left[u^{\prime}\left(y_{1}\right)+y_{1} u^{\prime \prime}\left(y_{1}\right)\right]-\gamma\left[u^{\prime}\left(y_{2}\right)+y_{2} u^{\prime \prime}\left(y_{2}\right)\right]\right\}} \\
& -\left[u^{\prime}\left(y_{1}\right)-\gamma u^{\prime}\left(y_{2}\right)\right]\left[-y_{1} u^{\prime}\left(y_{1}\right)+y_{2} u^{\prime}\left(y_{2}\right)\right] .
\end{aligned}
$$

(B1) vanishes if the relative risk aversion is constant, indicating that the workers' expected utility is independent of the probability of detection.

To determine how the probability of detection affects workers' expected utility if the relative risk aversion is not constant, observe that if $\beta=1 \Leftrightarrow \gamma=0$, then (B1) vanishes if $y_{2}$ converges to $y_{1}$, and its derivative with respect to $y_{2}$ is $u^{\prime}\left(y_{1}\right) u^{\prime}\left(y_{2}\right)\left[S\left(y_{2}\right)-S\left(y_{1}\right)\right]$. Accordingly, if $\beta=1$, the workers' expected utility increases with the probability of detection if $S\left(y_{2}\right)>S\left(y_{1}\right)$, and decreases with the probability of detection if $S\left(y_{2}\right)<S\left(y_{1}\right)$. 
Differentiating (A1) with respect to $\beta$ yields

$$
-\frac{\phi}{1-\phi}\left\{\left[u\left(y_{2}\right)-u\left(y_{1}\right)\right]\left[u^{\prime}\left(y_{2}\right)+y_{2} u^{\prime \prime}\left(y_{2}\right)\right]-u^{\prime}\left(y_{2}\right)\left[-y_{1} u^{\prime}\left(y_{1}\right)+y_{2} u^{\prime}\left(y_{2}\right)\right]\right\} .
$$

This derivative vanishes if $y_{1}$ converges to $y_{2}$, and differentiating it again with respect to $y_{1}$ yields $\phi(1-\phi)^{-1} u^{\prime}\left(y_{1}\right) u^{\prime}\left(y_{2}\right)\left[S\left(y_{1}\right)-S\left(y_{2}\right)\right]$. Since $y_{1}<y_{2}$, it follows that (A1) increases with $\beta$ if $S\left(y_{2}\right)>S\left(y_{1}\right)$ and decreases with $\beta$ if $S\left(y_{2}\right)<S\left(y_{1}\right)$. Consequently, for all $\beta$, if the relative risk aversion is increasing, the workers' expected utility increases with the probability of detection; conversely, if the relative risk aversion is decreasing, the workers' expected utility decreases with the probability of detection.

Reintroducing that the demand for labor is not completely inelastic (i.e., $1 / f^{\prime \prime}(\ell)<0$ ) does not change the sign of the expected-wage effect, but reduces its absolute value (except if the relative prudence equals two so that there is no expected-wage effect). Since the uncertainty effect is negative, the workers' expected utility increases with the probability of detection if their relative risk aversion is sufficiently increasing, but decreases with the probability of detection otherwise. 


\section{References}

Ashenfelter, O. and R.S. Smith, 1979, Compliance with the minimum wage law, Journal of Political Economy 87, 333-350.

Barsky, R.B.; Kimball, M.S.; Juster, F.T. and M.D. Shapiro, 1997, Preference parameters and behavioral heterogeneity, Quarterly Journal of Economics 112, 537-579.

Basu, A.K.; Chau, N. and R. Kanbur, 2009, Turning a blind eye: Costly enforcement, credible commitment and minimum wage laws, Economic Journal (forthcoming).

Burkhauser, R.V.; Couch, K.A. and D.C. Wittenburg, 2000, A reassessment of the new economics of the minimum wage literature with monthly data from the Current Population Survey, Journal of Labor Economics 18, 653-680.

Card, D. and Krueger, A.B., 1995, Myth and measurement: The new economics of the minimum wage (Princeton University Press, Princeton, NJ).

Chang, Y.M. and Ehrlich, I., 1985, On the economics of compliance with the minimum wage law, Journal of Political Economy 93, 84-91.

Cortes, K.E., 2005, Wage effects on immigrants from an increase in the minimum wage rate: An analysis by immigrant industry concentration, IZA Discussion Paper No. 1064.

Danziger, L., 2009, Endogenous monopsony and the perverse effect of the minimum wage in small firms, Labour Economics (forthcoming).

Deere, D.; Murphy, K.M. and F. Welch, 1995, Employment and the 1990-1991 minimumwage hike, American Economic Review P\&P 85, 232-237.

Dynan, K.E., 1993, How prudent are consumers?, Journal of Political Economy 101, 11041113.

Flodén, M., 2006, Labour supply and saving under uncertainty, Economic Journal 116, 721737.

Gindling, T.H. and K. Terrell, 2009, Minimum wages, globalization and poverty in Honduras, Labour Economics 16, 291-303.

Grenier, G., 1982, On compliance with the minimum wage law, Journal of Political Economy $90,184-187$. 
Guiso, L.; Jappelli, T. and D. Terlizzese, 1992, Earnings uncertainty and precautionary saving, Journal of Monetary Economics 30, 307-337.

Guiso, L. and M. Paiella, 2008, Risk aversion, wealth, and background risk, Journal of the European Economic Association 6, 1109-1150.

Kimball, M.S., 1990, Precautionary saving in the small and in the large, Econometrica 58, 53-73.

Neumark, D. and W. Wascher, 1992, Employment effects of minimum wages and subminimum wages: Panel data on state minimum wage laws, Industrial and Labor Relations Review 46, 55-81.

Neumark, D. and W. Wascher, 2007, Minimum wages and employment, Foundations and Trends in Microeconomics 3, 1-182.

Neumark, D.; Schweitzer, M. and W. Wascher, 2004, Minimum wage effects throughout the wage distribution, Journal of Human Resources 39, 425-450.

Parker, J.A., 1999, The reaction of household consumption to predictable changes in social security taxes, American Economic Review 89, 959-973.

Parker, S.C.; Belghitar, Y. and T. Barmby, 2005, Wage uncertainty and the labour supply of self-employed workers, Economic Journal 115, C190-C207.

Strobl, E. and F. Walsh, 2003, Minimum wages and compliance: The case of Trinidad and Tobago, Economic Development and Cultural Change 51, 427-450.

Weil, D., 2005, Public enforcement/private monitoring: Evaluating a new approach to regulating the minimum wage, Industrial and Labor Relations Review 58, 238-257.

Yaniv, G., 2001, Minimum wage noncompliance and the employment decision, Journal of Labor Economics 19, 596-603.

Yaniv, G., 2004, Minimum wage noncompliance and the sub-minimum wage rate, Economics Bulletin 10, 1-7.

Zavodny, M., 2000, The effect of the minimum wage on employment and hours, Labour Economics 7, 729-750. 